\title{
The indirect effect of social capital on performance through resilience capability - The case of State-Capital Enterprises in Vietnam (SCE)
}

\author{
Ngo Chin ${ }^{1 *}$, Nguyen Thuan ${ }^{2}$ \\ ${ }^{1}$ Office of the Government, Vietnam \\ ${ }^{2}$ Ho Chi Minh City Open University, Vietnam \\ *Corresponding author: ngochin2023@gmail.com
}

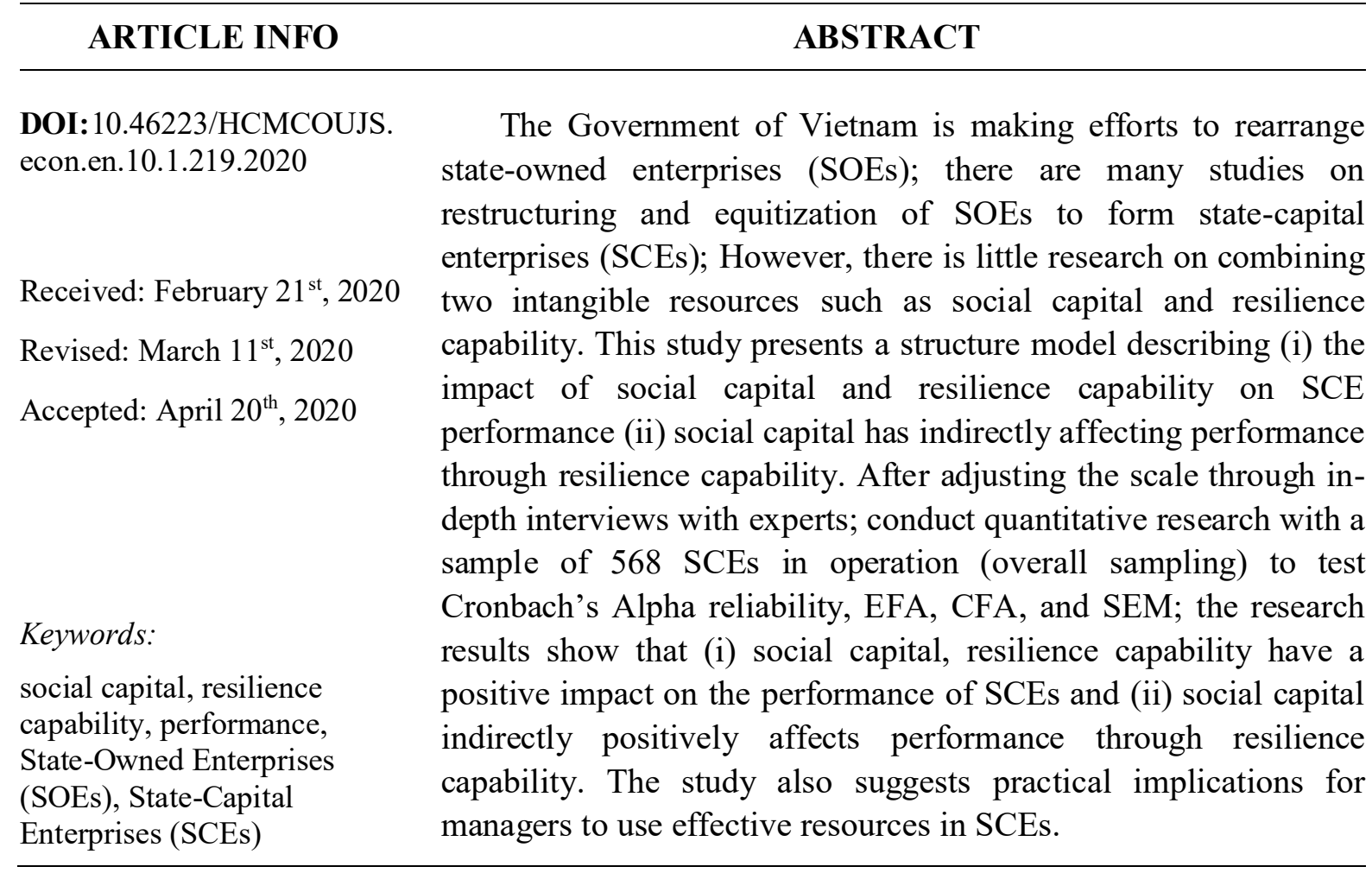

\section{Introduction}

After decades of establishment and development (1954 in the North and 1975 in the South), state-owned enterprises (SOEs) in Vietnam have contributed to the overall stability of the economy. However, SOEs have exposed too many weaknesses from capital management to the use of other physical resources such as land and factories. Therefore, the Government of Vietnam is making efforts to rearrange SOEs. There are many studies on restructuring and equitization of SOEs to form State-capital enterprises (SCEs). SCE is an enterprise in which the State holds less than $100 \%$ of charter capital or shares, the contributed capital may not dominate; organized and operated in the form of a joint-stock company or a two-member limited liability company. The previous researches show that social capital affects the resilience capability of enterprises (Johnson, 2010) and social capital also helps to handle difficult situations in time (Putnam, 1995, 2000); Social capital is effective in reducing risks, contributing to improving performance (Casey, 2002; Woolcock, 2001; Narayan \& Pritchett, 1999; Dasgupta, 2000); resilience capability also has a positive direct relationship with performance when environmental turbulences (Chu, 2015); but no studies have looked at the aggregate resources (social capital combined with resilience capability) that have mutual influence and impact on the performance of SCEs in the Vietnamese context. 
This study corrected the scales (social capital, resilience capability, and performance) by conducting in-depth interviews with experts to formulate a quantitative questionnaire. A survey was conducted at SCEs to collect data. The final sample used for analysis is of 568 SCEs. Test of reliability of Cronbach's Alpha and EFA was performed via SPSS 22.0; AMOS 22.0 was employed to analyze EFA, CFA, and test of models and hypotheses by SEM. Research results show that (i) social capital, resilience capability have a positive impact on the performance of SCEs; and (ii) social capital indirectly positively affects performance through resilience capability. The study also proposes solutions to use social capital, resilience capability to improve the performance of SCEs.

\section{Literature review}

\subsection{Main concepts}

Social capital: social capital is a concept that has been mentioned a lot in the fields of economics, education, society, psychology, ..., social capital in the most basic way of understanding includes (1) System of networks, (2) Human trust, and (3) Interconnection to do the job. Social capital is studied at different levels: individuals, organizations, businesses.

In this study, corporate social capital is defined as the aggregation of enterprise resources (Bourdieu \& Wacquant, 1992) that exist in quality relationship networks with a structure of networks comprising: the network of the leader (Tushman, 1997), external network of the enterprise (Yang, Brashear Alejandro, \& Boles, 2011) and the internal network of the enterprise (Brookes, Morton, Dainty, \& Burns, 2006).

Resilience capability: resilience capability is maintaining positive adjustments under challenging conditions (Weick, Sutcliffe, \& Obstfeld, 2008). The structure of resilience capability consists of four components (Chu, 2015): anticipatory (AT), adaptability (AD), agility (AG), and flexibility (FL).

Researchers propose that businesses should build resilience capability by focusing on capacity and growth (Sutcliffe \& Vogus, 2003); exploitation and exploration (March, 1991); maintain competitive advantage by managing performance and resilient systems (Robb, 2000). The core elements of resilience capability are the ability to react, respond and adjust positively under uncertain, challenging conditions, environment turbulences; the ability of agility and flexibility (Chu, 2015) in allocating resources appropriately to ensure the sustainable operation of enterprises.

Performance: performance is measured in a variety of ways including assessing business success (Kennerley \& Neely, 2003); quantifying the results and effectiveness of managing an organization's operations (Neely, Gregory, \& Platts, 1995). Performance can also be measured through the application of objective and subjective indicators. Chu (2015) is a typical use of a scale to measure the performance of enterprises, with 3 measurement scales including (1) Profit or profitability (PR), (2) customer satisfaction (SA), and (3) market efficiency (ME).

\subsection{Hypotheses development}

Measurement of social capital is considered in three corresponding angles: the social capital of leader (LD), external social capital (EX), and internal social capital (IN) of the enterprise (Huynh, 2012).

When the leader has the ability, high qualifications, good quality (high LD) will have a good relationship with the Government levels and media organizations (Tushman, 1997), helping 
businesses overcome difficulties and challenges; foresee possible bad situations; always be proactive and adapt well to the environment. As such, the social capital of the leader will help improve resilience capability.

Well-built internal social capital (high IN) will promote cooperation, support, coordination, and sharing of knowledge and experience internally (Brookes et al., 2006); internal social capital creates stability because of high trust and consensus; This helps businesses to be proactive to adjust and respond well to changes of the environment; thus, the internal social capital helps to improve the resilience capability.

External social capital is well established (high EX), the horizontal and vertical relationships will be good (Yang et al., 2011), especially for consulting organizations (horizontal) and government levels (vertical) will help for businesses to be able to predict and adapt well to changes in the environment; so external social capital also helps to improve resilience capability.

Social capital affects the resilience capability of the enterprise (Johnson, 2010) and social capital also helps to handle difficult situations in time (Putnam, 1995, 2000); previous studies have shown that social capital has a positive influence on resilience capability; however, few studies in Vietnam have addressed this issue, especially for SCEs; so this study proposes the following hypothesis:

H1: The social capital has a positive effect on the resilience capability of SCEs in Vietnam

Corporate social capital consists of three components: the social capital of leader, internal social capital, and external social capital (Huynh, 2012).

Leaders with high social capital (high LD) will have a lot of positive relationships and timely and quick information support from Government levels and media organizations (Tushman, 1997), thus contributing to high results in the operation process; help improve performance.

Well-built internal social capital (high IN) will help promote proactive cooperation; help support, share and trust each other (Brookes et al., 2006); contribute to reducing transaction costs; helping to use resources effectively, so that enterprises' efficiency can be improved.

Good external social capital (high EX) will help improve vertical and horizontal relationships (Yang et al., 2011), especially for advisory organizations (horizontal) and with government levels (vertical) that will provide businesses useful information, advice to get ready for the opportunity, help improve the performance of businesses.

Social capital is effective in reducing risks, contributing to improving operational efficiency (Casey, 2002; Dasgupta, 2000; Narayan \& Pritchett, 1999; Woolcock, 2001); previous studies have shown that social capital has a positive impact on performance, but few studies in Vietnam address this issue, especially for SCEs, so this study proposes the following hypothesis:

\section{H2: The social capital has a positive effect on the performance of SCEs in Vietnam}

Resilience capability helps businesses always be in a proactive state to maintain positive adjustments under challenging conditions (Weick et al., 2008) to respond well the environment turbulences, thus creating favorable conditions for businesses to have many opportunities to gain competitive advantage; leading in product innovation and technological innovation to meet market 
demands, increase customer satisfaction, increase profits and market efficiency. Resilience capability also has a positive direct relationship with performance when environmental fluctuations (Chu, 2015). Thus, the resilience capability helps to improve performance; there are many foreign studies on the resilience capability in volatile environments but few studies in Vietnam address this issue, especially for SCEs; the research proposes the following hypothesis:

\section{H3: Resilience capability has a positive effect on the performance of SCEs in Vietnam}

\section{Research method}

This study used a mixed model of both qualitative and quantitative methods with quantitative methods as the key. The qualitative research used in-depth interview methods with 10 experts (leaders of SCEs in Vietnam with ages ranging from 40 to 55; males all and at least tenyear experience of SCEs in Vietnam) to explore new indicators to adjust and complete the constructs in the research model. The quantitative research applied the survey of leaders of SCEs in Vietnam with overall sampling. A sample of 720 respondents was targeted and a total of 571 questionnaires were completed with a return rate of about $80 \%$ (the remains withdraw state capital). Three invalid and uncompleted questionnaires were rejected, resulting in 568 valid answer sheets used to analyze in this research.

Research process: Adjusting the scale by in-depth interview method with experts; building hypotheses and research model; Official quantitative research of the sample size of 568 SCEs in Vietnam; testing scales with SPSS 22.0 software to calculate Cronbach's Alpha reliability coefficient and EFA analysis; using AMOS 22 software to analyze CFA; test the research model by using SEM linear structural equation model tool; retest the model with Bootstrap with sample size $\mathrm{N}=1000$ to conclude the model and the hypotheses about the impact of social capital, resilience capability to the performance of SCEs in Vietnam.

Scales building: The scale of leader social capital (LD) has 5 items (from LD1 to LD5); the scale of internal social capital (IN) has 3 items (from IN1 to IN5); the scale of external social capital (EX) has 7 items (from EX1 to EX7); these scales are of enterprise social capital factor adapted and developed from the research of Huynh (2012).

The scale of adaptability (AD) has 4 items (from AD1 to AD4); the scale of anticipatory (AT) has 6 items (from AT1 to AT6); the scale of agility (AG) has 7 items (from AG1 to AG7); the scale of flexibility (FL) has 6 items (from FL1 to FL6); these scales are of resilience capability factor inherited from the research of Chu (2015).

The scale of customer satisfactory (SA) has 3 items (from SA1 to SA3); the scale of profitability (PR) has 3 items (from PR1 to PR3); the scale of market effectivity (ME) has 3 items (from ME1 to ME3); these scales are of enterprise performance factor inherited from the research of Chu (2015).

\section{Results of preliminary quantitative research}

This is done by sending 100 questionnaires to SCEs and collecting 60 qualified copies. The results showed that 10 scales of 3 research concepts all met the requirements of the content of each observed variable, about Cronbach alpha and EFA for each concept. 


\section{Results}

\subsection{Survey results, sample profile}

\section{Characteristics of surveyed enterprises:}

Most types of enterprises are joint-stock companies with agricultural capital accounting for $35.7 \%$; the main field of activity is manufacturing, construction up to $49.6 \%$; the number of major branches from 1 to 5 branches accounts for $30.6 \%$; the structure of state capital is slow; equitization area reached $100 \%$ in the sample; the equitization year focused heavily on the period 2018-2019 due to the time close to collecting information; business results mostly range from normal to very good.

\section{Characteristics of surveyed individuals:}

Male and female gender equivalent; respondents aged 41-50 accounted for the majority of $34.7 \%$; university education accounts for the majority of $49.9 \%$; the leadership positions that answer most are deputy directors to general directors; the main task is senior manager reaching $25.2 \%$; the common working time in enterprises in group 1 to 6 years is $26.4 \%$; working time in state-owned enterprises concentrated much about 5 to 10 years, accounting for $36.1 \%$.

\subsection{Testing scales by reliability Cronbach's Alpha and EFA}

Cronbach's Alpha reliability coefficient of 10 scales of 3 concepts all variables have a coefficient of item - total (item - total correlation) greater than 0.5. All scales meet the Cronbach's Alpha reliability coefficient $(\alpha L D=0.839 ; \alpha E X=0.874 ; \alpha I N=0.766 ; \alpha A D=0.877 ; \alpha A T=$ $0.889 ; \alpha A G=0.912 ; \alpha F L=0.897 ; \alpha S A=0.852 ; \alpha P R=0.868 ; \alpha M E=0.846)$.

The EFA analysis result shows the value of $0.5 \leq \mathrm{KMO}=0.918 \leq 1$; total variance extracted $=60,053>50 \%$ at eigenvalue $=1,211>1$; the maximum factor load factor of each observed variable is $\geq 0.5$, it shows that the factor analysis is consistent with the survey data, there are 47 measurement variables (items) for 10 scales continue to be used in the model. All scales are standard for carrying out official quantitative research in CFA.

\subsection{CFA analysis}

The CFA result of the social capital factor of the SCEs show that: Chi-squared $=145,389$, $\mathrm{p}=0,000$. Models with degrees of freedom $\mathrm{df}=87>0$, Chi-squared $/ \mathrm{df}=1,671 \leq 2$ should be qualified; $0.9 \leq \mathrm{GFI}=0.967 \leq 1 ; 0.9 \leq \mathrm{TLI}=0.980 \leq 1 ; 0.9 \leq \mathrm{CFI}=0.983 \leq 1$ so 3 indicators are very satisfied. RMSEA index $=0.034<0.05$, so the model is very suitable for the whole. The three scales LD, IN and EX all achieve unidimensionality. The scales of LD and IN (estimate 0.583), IN and EX (estimate 0.567), LD and EX (estimate 0.552) have discriminant validity. The observed variables measure three components $L D, I N$ and EX achieving convergent validity (lowest $\lambda_{E X}=$ .576); composite reliability, extracted variance of scales LD (0.840 and 0.512), IN (0.767 and $0.524)$ and EX (0.875 and 0.506) are satisfactory. The indicators show that the SEM model of social capital is consistent with market data.

The CFA result of the resilience capability factor of SCEs show that: Chi-squared = $578,013, \mathrm{p}$-value $=0.000$, have degrees of freedom $\mathrm{df}=224>0$, Chi-squared $/ \mathrm{df}=2,580 \leq 3$ should meet standards; $0.9 \leq \mathrm{GFI}=0.920 \leq 1 ; 0.9 \leq \mathrm{TLI}=0.950 \leq 1 ; 0.9 \leq \mathrm{CFI}=0.956 \leq 1$ so 3 indicators are very satisfied. RMSEA $=0.053<0.08$, so the model is suitable for the whole. The four scales of AT, AD, AG and FL all achieve unidimensionality. The scales of AT and AD 
(estimate 0.555), AT and AG (estimate 0.636), AT and FL (estimate 0.654); AD and AG (estimate 0.469), $\mathrm{AD}$ and FL (estimate 0.482), $\mathrm{AG}$ and FL (estimate 0.619) are discriminant validity. The observed variables measure the four components AT, AD, AG and FL to achieve the convergent validity ( lowest $\lambda_{\mathrm{AG} 7}=.579$,); composite reliability, extracted variance of scales of AT $(0.890$ and 0.574$), \mathrm{AD}(0.878$ and 0.642$), \mathrm{AG}(0.914$ and 0.605$)$ and $\mathrm{FL}(0.900$ and 0.600$)$ are satisfactory. The indicators all show the SEM model of resilience capability in line with market data.

The CFA result of the performance factor of SCEs show that: Chi-squared $=47.154, \mathrm{p}$ value $=0.003$, degrees of freedom $\mathrm{df}=24>0$, Chi-squared $/ \mathrm{df}=1,965 \leq 2$ should meet standards; $0.9 \leq \mathrm{GFI}=0.982 \leq 1 ; 0.9 \leq \mathrm{TLI}=0.986 \leq 1 ; 0.9 \leq \mathrm{CFI}=0.991 \leq 1$ so 3 indicators are very satisfied. RMSEA index $=0.041<0.05$, so the model is very suitable for the whole. The three scales SA, PR and ME all achieve unidimensionality. The scales PR and ME (estimate 0.406), SA and ME (estimate 0.455), PR and SA (estimate 0.399) reach discriminant validity. The observed variables measure the three components $\mathrm{SA}, \mathrm{PR}$ and $\mathrm{ME}$ achieving convergent validity ( lowest $\left.\lambda_{S A 3}=.742\right)$; Composite reliability, extracted variance of the SA (0.691 and 0.652), PR (0.870 and 0.691) and ME (0.847 and 0.648) scales are satisfactory; The indicators all show the SEM model of operational efficiency consistent with market data.

The CFA result of the three factors in the critical measurement model of SCEs show that: Chi-squared $=1666,599, \mathrm{p}$-value $=0.000$, have degrees of freedom $\mathrm{df}=1021>0$, Chi-squared $/ \mathrm{df}$ $=1,632 \leq 2 ; 0.8<\mathrm{GFI}=0.889 \leq 1 ; 0.9 \leq \mathrm{TLI}=0.953 \leq 1 ; 0.9 \leq \mathrm{CFI}=0.955 \leq 1$ so 3 indices satisfy. RMSEA index $=0.033<0.05$, so the model is very suitable for the whole. The three concepts of social capital, resilience capability, and performance are all unidimensionality. The concept of social capital and resilience capability (estimate 0.245 ); social capital and performance (estimate 0.372); resilience capability and performance (estimate 0.421) all reach discriminant validity. Observed variables measure three components LD, IN and EX; four components: AT, $\mathrm{AD}, \mathrm{AG}$ and FL; the three components $\mathrm{SA}, \mathrm{PR}$ and ME all achieve convergent validity ( lowest $\left.\lambda_{P R}=.550\right)$; composite reliability, extracted variance of the concept of social capital (0.797 and $0.567)$, resilience capability ( 0.845 and 0.578$)$ met requirements; composite reliability, extracted variance of performance (0.684 and 0.422$)$ are nearly reached. SEM result of the standardized structural model show that the theoretical model is consistent with market data.

\subsection{SEM test}

The three hypotheses H1, H2 and H3 are accepted statistically at 99\% level of confidence and yield the following estimates of linear relationship:

Social capital --> resilience capability $(0.245)$

Social capital --> operational efficiency $(0.286)$

Resilience capability --> operational efficiency (0.351)

SEM result of the standardized structure model show that the theoretical model is appropriate with the survey data (Chi-squared $/ \mathrm{df}=1,632 \leq 2 ; 0.8<\mathrm{GFI}=0.889 \leq 1 ; 0.9 \leq \mathrm{TLI}=$ $0.953 \leq 1 ; 0.9 \leq \mathrm{CFI}=0.955 \leq 1$, so the 3 indexes are satisfactory. $\mathrm{RMSEA}=0.033<0.05$, so the model fits the overall). 


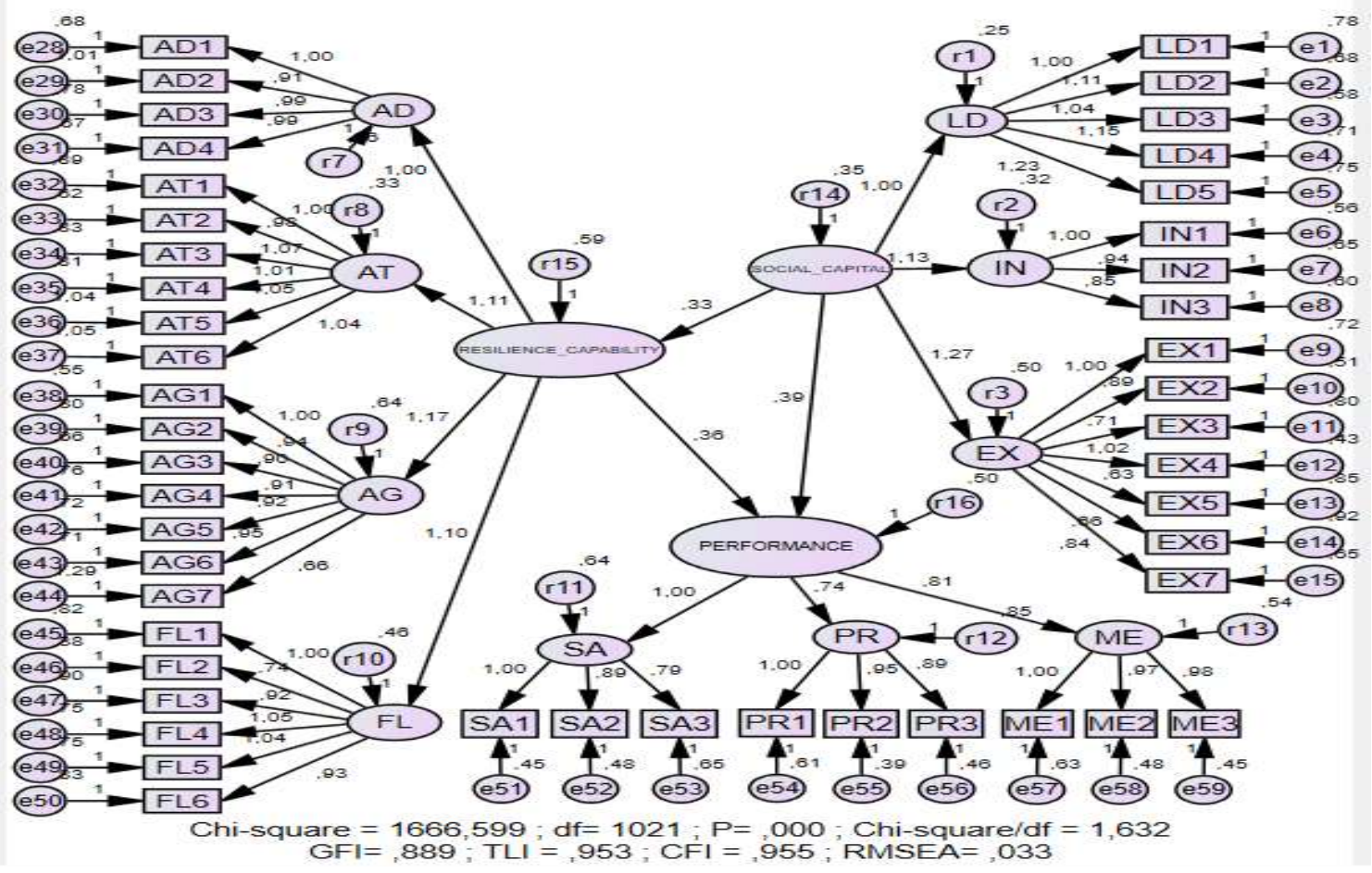

Figure 1. Data analysis result of the research

This study uses Bootstrap with the number of repeating samples $\mathrm{N}=1000$, with the critical value C.R is less than 1.96 so the estimates in the model are highly reliable.

\section{Implication and future research}

\subsection{Theoretical implications}

Firstly, This study examines the impact of social capital, resilience capability on the performance of SCEs in Vietnam; a specific type of enterprise is in the process of transformation, restructuring to perfection.

Secondly, This study confirmed the combined intangible resources including social capital, resilience capability having their impacts on the performance of SCEs in Vietnam.

Thirdly, This study contributed to the improvement of the resilience capability scale by identifying the observed variables for components that are appropriate for SCEs in Vietnam.

Fourthly, This study proved that social capital had an indirect effect on performance through the resilience capability of SCEs in Vietnam.

Fifthly, This study presented a second-order factor structure model that represents the correlation between factors (social capital had a positive effect on resilience capability and operational efficiency; resilience capability had a positive effect on performance); affirming the importance and influence of the above factors on the performance of SCEs in Vietnam.

\subsection{Managerial implication}

Firstly, raising awareness of the spirit of initiative and coordination: smoothly combining intangible social capital resources, resilience capability; improve the spirit of coordination of 
individuals and departments in the enterprise in a proactive, creative and innovative way; coordinate in predicting and forecasting quickly and promptly; allocating resources in a quick, flexible and appropriate manner; the spirit of coordination is the foundation for individuals to contribute to the construction of SCEs in Vietnam.

Secondly, eliminate dependence and avoid collisions: dismantling the state subsidy mechanism is the basis of dependence and dependence of SCEs in Vietnam.

Thirdly, focusing on the sustainability of the operation and life cycle of SCEs in Vietnam: not for the huge profit in the short term but forgetting to plan a stable and sustainable development strategy over time.

Fourthly, effective exploitation, use, and coordination of intangible resources: SCEs in Vietnam need to identify each intangible resources and their importance to ensure that SCEs in Vietnam can compete healthily with other types; their importance in indirectly effectively exploiting tangible physical resources of enterprises and operate effectively in the long run, meeting the expectations of the Vietnamese Government.

Fifthly, reasonable performance allocation and terminating thinking in administration term: SCE managers in Vietnam also have term tenure thinking so they often care about what happens in the short term; do what is beneficial for the immediate future, but also invest, plan for the far future is not interested; for SCEs in Vietnam to operate effectively and sustainably, they must reasonably allocate the achievements of businesses and eliminate the tenure mindset.

\subsection{Limitations and future research}

Firstly, the research data collected in this study by the non-probability sampling method can make the representative of the sample not high.

Secondly, this study was conducted for only one type of SCE enterprise in Vietnam, and there may be differences in the measurement scale in other types of enterprises.

Thirdly, the scope of this study was conducted throughout the territory of Vietnam; survey questionnaires collected have scattered allocation in many sectors and fields. Further research should take research data in specific areas.

Fourthly, this study is conducted in the Vietnamese context; further studies should be conducted in countries with transition economies such as Vietnam.

In brief, this study achieved its goal of general research by combining two intangible resources social capital and resilience capability; these resources indirectly increase the exploitation of tangible physical resources and increase the performance of SCEs in Vietnam.

\section{References}

Bourdieu, P. (2011). The forms of capital (1986). In I. Szeman \& T. Kaposy (Eds.), Cultural theory: An anthology (1st ed., pp. 81-93). Hoboken, NJ: John Wiley \& Sons.

Bourdieu, P., \& Wacquant, L. J. (1992). An invitation to reflexive sociology. Chicago, IL: University of Chicago Press.

Brookes, N. J., Morton, S. C., Dainty, A. R. J., \& Burns, N. D. (2006). Social processes, patterns and practices and project knowledge management: A theoretical framework and an empirical investigation. International Journal of Project Management, 24(6), 474-482. doi:10.1016/j.ijproman.2006.03.005 
Casey, T. (2002). The social context of economic change in Britain: Between policy and performance. Manchester, UK: Manchester University Press.

Chen, C. N., Tzeng, L. C., Ou, W. M., \& Chang, K. T. (2007). The relationship among social capital, entrepreneurial orientation, organizational resources and entrepreneurial performance for new ventures. Contemporary Management Research,3(3), 213-232. doi: $10.7903 / \mathrm{cmr} .90$

Chu, Y. H. (2015). Resilience capabilities in the face of environmental turbulence: A case of Hong Kong small to medium enterprises (Doctoral dissertation, School of Management, College of Business, RMIT University). Retrieved January 11, 2020, from https://core.ac.uk/reader/32239645

Coleman, J. S. (1994). Social capital, human capital, and investment in youth. In A. C. Petersen \& J. T. Mortimer (Eds.), Youth unemployment and society (pp. 34-50). Cambridge, UK: Cambridge University Press. doi:10.1017/CBO9780511664021.004

Dasgupta, P. (2000). Economic progress and the idea of social capital. In P. Dasgupta \& I. Serageldin (Eds.), Social capital: A multifaceted perspective (pp. 325-424). Washington, DC: World Bank Publications.

Fukuyama, F. (2001). Social capital, civil society and development. Third World Quarterly, 22(1), 7-20. doi:10.1080/01436590020022547

Johnson, N. (2010). Social capital and organizational resilience (Doctoral dissertation, University of Liverpool). $\quad$ Retrieved January 12, 2020, from https://livrepository.liverpool.ac.uk/2775/7/JohnsonNoe_June2010_2775.pdf

Hair, J. F., Black, W. C., Babin, B. J., \& Anderson, R. E. (2010). Multivariate data analysis: A global perspective. Upper Saddle River, NJ: Pearson Prentice Hall.

Hoang Trong, \& Chu, N. M. N. (2008). Phân tích dũ liệu nghiên cúu với SPSS (tập 2) [Analyzing research data with SPSS (episode 2)]. Ho Chi Minh City, Vietnam: Hồng Đức.

Huynh, D. T. (2012). Social capital and enterprise performance. A case of real estate enterprises in Vietnam.

Kennerley, M., \& Neely, A. (2003). Measuring performance in a changing business environment. International Journal of Operations \& Production Management, 23(2), 213-229. doi:10.1108/01443570310458465

Lengnick-Hall, C. A., Beck, T. E., \& Lengnick-Hall, M. L. (2011). Developing a capacity for organizational resilience through strategic human resource management. Human Resource Management Review, 21(3), 243-255. doi:10.1016/j.hrmr.2010.07.001

March, J. G. (1991). Exploration and exploitation in organizational learning. Organization Science, 2(1), 71-87.

Narayan, D., \& Pritchett, L. (1999). Cents and sociability: Household income and social capital in rural Tanzania. Economic Development and Cultural Change,47(4), 871-897. doi: $10.1086 / 452436$ 
Neely, A., Gregory, M., \& Platts, K. (1995). Performance measurement system design: A literature review and research agenda. International Journal of Operations \& Production Management, 15(4), 80-116. doi:10.1108/01443579510083622

Nguyen, H. T., \& Huynh, D. T. (2010). Xây dựng khung phân tích vốn xã hội trong DN cho điều kiện Việt Nam, tổng quan lý thuyết và các nghiên cứu thực nghiệm [Developing an analytical framework of social capital in enterprises for Vietnamese, theoretical overview and empirical studies]. Journal of Development and Integration, 6, 22-28.

Oktemgil, M., \& Greenley, G. (1997). Consequences of high and low adaptive capability in UK companies. European Journal of Marketing, 31(7), 445-466. doi:10.1108/03090569710176619

Putnam, R. D. (1995). Capital social e democracia. Braudel Papers, 10, 175-187.

Putnam, R. D. (2000). Bowling alone: America's declining social capital. In L. Crothers \& C. Lockhart (Eds.), Culture and politics (pp. 223-234). New York, NY: Palgrave Macmillan. doi:10.1007/978-1-349-62397-6_12

Robb, D. (2000). Building resilient organizations resilient organizations actively build and integrate performance and adaptive skills. Od Practitioner, 32(3), 27-32.

Sutcliffe, K. M., \& Vogus, T. J. (2003). Organizing for resilience. In K. S. Cameron, J. E. Dutton, \& R. E. Quinn (Eds.), Positive organizational scholarship: Foundations of a new discipline (pp. 94-110). Oakland, CA: Berrett-Koehler.

Tushman, M. L. (1997). Winning through innovation. Strategy \& Leadership, 25(4), 14-19. doi:10.1108/eb054591

Weick, K. E., \& Sutcliffe, K. M. (2001). Managing the unexpected (Vol. 9). San Francisco, CA: Jossey-Bass.

Weick, K. E., Sutcliffe, K. M., \& Obstfeld, D. (2008). Organizing for high reliability: Processes of collective mindfulness. Crisis Management, 3(1), 81-123.

Woolcock, M. (2001). The place of social capital in understanding social and economic outcomes. Canadian Journal of Policy Research, 2(1), 11-17.

Yang, J., Brashear Alejandro, T. G., \& Boles, J. S. (2011). The role of social capital and knowledge transfer in selling center performance. Journal of Business \& Industrial Marketing, 26(3), 152-161. doi:10.1108/08858621111115877 